\title{
HUBUNGAN PENGETAHUAN PERAWAT TENTANG GAGAL JANTUNG DENGAN PENATALAKSANAAN PASIEN GAGAL JANTUNG DI RUANG IGD RSUD SUMBAWA BESAR.
}

\author{
Dina Fithriana $^{1}$, Agus Putradana ${ }^{2}$, Antoni Eka Fajar Maulana ${ }^{3}$ \\ ${ }^{1,2,3)}$ Sekolah Tinggi Ilmu Kesehatan (STIKES) Mataram \\ dinafithriana@ymail.com
}

\begin{abstract}
ABSTRAK
Unit Gawat Darurat (UGD) adalah unit pelayanan di Rumah Sakit yang memberikan pelayanan pertama pada pasien dengan ancaman kematian dan kecacatan secara terpadu dengan melibatkan berbagai multidisiplin. Serangan jantung dan problem seputarnya masih menjadi pembunuh nomor satu dengan raihan $29 \%$. Kematian global setiap tahun, mencatat sekitar 17 juta orang meninggal karena penyakit sistem kardiovaskuler dan sekitar 32 juta mengalami serangan jantung setiap tahunnya dan pada tahun 2030 sekitar 23,6 juta orang akan meninggal karena penyakit sistem Kardiovaskuler.

Metode penelitian menggunakan deskriptif analitik dengan analisa data Uji korelasi Sperman Rank. Subyek penelitian adalah semua perawat yang berada di ruang IGD RSUD Sumbawa Besar. Di dapat responden penelitian sebanyak 22 orang yang ditentukan dengan Tehnik total sampling.

Hasil diolah dengan menggunakan uji korelasi spearman Rank. Dari hasil uji Spearman Rank di dapatkan bahwa hubungan pengetahuan perawat tentang gagal jantung dengan penatalaksanaan pasien gagal jantung dengan Rho hitung > Rho tabel $0,4602>0,428$. Maka Ho ditolak dan Ha diterima berarti ada Hubungan yang signifikan antara pengetahuan perawat tentang gagal jantung dengan penatalaksanaan pasien gagal jantung di ruang IGD RSUD Sumbawa Besar.

Dari hasil penelitian, ini menunjukankan semakin tinggi pengetahuan perawat maka akan semakin tinggi pengetahuan perawat dalam penatalaksanaan pasien gagal jantung di IGD RSUD Sumbawa Besar.
\end{abstract}

Kata kunci: Pengetahuan Perawat, Penatalaksanaan Pasien Gagal Jantung.

\section{PENDAHULUAN}

Unit Gawat Darurat (UGD) adalah unit pelayanan di Rumah Sakit yang memberikan pelayanan pertama pada pasien dengan ancaman kematian dan kecacatan secara terpadu dengan melibatkan berbagai multidisiplin. Pelayanan keperawatan gawat darurat yang diberikan meliputi pelayanan keperawatan yang ditujukan kepada pasien gawat darurat yaitu pasien yang tiba-tiba berada dalam keadaan gawat dan terancam nyawanya atau anggota badannya (akan menjadi cacat) bila tidak mendapat pertolongan secara cepat dan tepat, bantuan kegawatdaruratan ini mencakup banyak organ penting tubuh antara lain sistem kardiovaskular dimana masih tingginya angka kematian akibat serangan penyakit sistem kardiovaskular ini dan dua pertiganya meninggal dalam dua jam setelah serangan (Direktorat, 2005).

Tingginya angka kematian di ruang Instalasi Gawat Darurat (IGD) erat kaitannya dengan beberapa faktor diantaranya: 1. Respon time; 2. Brainware yakni sumber daya manusia yang terdiri dari dokter spesialis, dokter 
umum dan perawat baik secara kuantitas maupun kualitas; 3. Hardware yakni perangkat yang terdiri dari fasilitas, peralatan dan obat-obatan; 4. Software yakni perangkat lunak yang terdiri dari organisasi, tata kerja, protap (prosedur tetap dan diklat) (Depkes RI, 2002).

WHO (2008), menerangkan bahwa penyakit jantung dengan penyakit infeksi dan kanker masih tetap mendominasi peringkat teratas penyebab utama kematian di dunia. Serangan jantung dan problem seputarnya masih menjadi pembunuh nomor satu dengan raihan $29 \%$. Kematian global setiap tahun, mencatat sekitar 17 juta orang meninggal karena penyakit sistem kardiovaskuler dan sekitar 32 juta mengalami serangan jantung setiap tahunnya dan pada tahun 2030 sekitar 23,6 juta orang akan meninggal karena penyakit sistem Kardiovaskuler.

Demikian juga halnya di Indonesia, berdasarkan Riset Kesehatan Dasar Riskesdas 2010, menunjukan bahwa Prepalensi penyakit jantung secara nasional adalah 7,2\%. Resiko terjadinya gagal jantung akan terus meningkat seiring dengan bertambahnya usia karena $10 \%$ orang yang berusia diatas 75 tahun mempunyai kecenderungan menderita gagal jantung.

Penyakit jantung iskemik mempunyai proporsi sebesar $5,1 \%$ dari seluruh penyakit penyebab kematian di Indonesia, dan penyakit jantung mempunyai angka proporsi $4,6 \%$ dari seluruh kematian dimana penyebab kematian nomor satu di Indonesia adalah Stroke.

Prevalensi penyakit jantung di NTB tahun 2007 yaitu 9,2\% (sekitar 2,7-14,5\%), jauh lebih tinggi dari angka nasional $(6,98 \%)$ (RISKESDAS Provinsi Nusa Tenggara Barat, 2007).

RSUD Sumbawa Besar sebagai salah satu Rumah Sakit Umum daerah yang menjadi rujukan puskesmas sekitar berdasarkan data pada tahun 2010 dan 2011 di instalasi gawat darurat RSUD Sumbawa Besar menunjukkan adanya peningkatan jumlah kunjungan pasien gagal jantung dimana pada tahun 2010 sebanyak 65 kasus dan pada tahun 2011 sebanyak 75 kasus dan Pada tahun 2012 mengalami peningkatan sebanyak 85 kasus. (RSUD Sumbawa).

Kualitas dari tenaga keperawatan di instalasi gawat darurat tercermin dari pengetahuan, dan keterampilan yang dimilikinya. Seorang perawat yang memiliki pengetahuan baik kemungkinan besar ia akan memiliki keterampilan yang memadai dalam memberikan pertolongan pada pasien gagal jantung.

Upaya yang dilakukan meminimalkan tingkat kematian di instalasi gawat darurat (IGD) antara lain adalah dengan cara memberikan pelatihan bagi perawat yang bekerja di IGD tentang bantuan hidup dasar/basic life support $(B L S)$. Khususnya dalam hal penantalaksanaan pasien gagal jantung. Dari 22 orang perawat 8 orang telah mendapat pelatihan bantuan hidup dasar pada tahun 2008-2009. Setelah itu belum ada yang ikut pelatihan tentang bantuan hidup dasar basic life support (BLS) khususnya dalam hal penatalaksanaan pasien gagal jantung.

Bantuan hidup dasar/basic life support $(B L S)$ merupakan usaha yang dilakukan untuk mempertahankan kehidupan pada saat penderita mengalami keadaan yang mengancam nyawa (pasien mengalami gagal jantung) tanpa menggunakan terapi cairan intra vena, obat-obatan dan kejut listrik. Sebaliknya bila usaha untuk mempertahankan kehidupan pada saat penderita mengalami keadaan yang mengancam nyawa memakai cairan intra vena, obat-obatan dan kejut listrik maka dikenal sebagai bantuan hidup lanjut (Advances life support) (Syamsudin, 2011). 
Dari uraian diatas peneliti merasa tertarik untuk mengetahui lebih lanjut tentang "Hubungan pengetahuan perawat tentang gagal jantung dengan penatalaksanaan pasien gagal jantung di RSUD Sumbawa Besar.

\section{METODE PENELITIAN}

Metode penelitian menggunakan deskriptif analitik dengan analisa data Uji korelasi Sperman Rank. Subyek penelitian adalah semua perawat yang berada di ruang IGD RSUD Sumbawa Besar. Di dapat responden penelitian sebanyak 22 orang yang ditentukan dengan Tehnik total sampling. Analisa data dalam penelitian ini adalah menggunakan Uji Spearman Rank dengan Ha diterima apabila Rho hitung $>$ Rho tabel.

Pengetahuan perawat tentang gagal jantung adalah hasil tahu dan paham perawat tentang Gagal Jantung yang meliputi definisi, etiologi, klasifikasi, pemeriksaan penunjang dan penatalaksanaannya. Data pengetahuan perawat tentang gagal jantung didapatkan melalui kuesioner yang diberikan kepada perawat yang berdinas di ruang IGD RSUD Sumbawa.

Sedangkan Penatalaksanaan pasien Gagal Jantung adalah prosedur penanganan yang diberikan pada pasien gagal jantung di IGD RSUD Sumbawa. Data penatalaksanaan ini didapatkan dari hasil observasi yang dilakukan peneliti kepada perawat yang berdinas di ruang IGD yang menangani pasien gagal jantung.

\section{HASIL PENELITIAN}

1. Data Umum

Penelitian ini dilakukan di instalasi gawat darurat (IGD) RSUD Sumbawa Besar. Instalasi gawat darurat merupakan pelayanan tingkat lanjut yang harus diberikan secepatnya untuk mencegah resiko kematian atau cacat, diselenggarakan secara terus menerus selama 24 jam.

Dalam memberikan pelayanan kepada masyarakat, saat ini di IGD RSUD Sumbawa Basar didukung oleh 5 orang Dokter umum, 22 orang tenaga perawat, 2 orang tenaga bidan. Semua tenaga tersebut terbagi dalam 3 shift yaitu shift pagi, shift siang, shift malam.

a. Distribusi Data Perawat IGD Berdasarkan Umur

Tabel 1.1 Distribusi Perawat IGD Berdasarkan Usia

\begin{tabular}{|c|c|c|c|}
\hline No & Usia & Jumlah & $\begin{array}{c}\text { Prosentase } \\
\%\end{array}$ \\
\hline 1 & $20-30$ tahun & 15 & 68 \\
\hline 2 & $31-40$ tahun & 7 & 32 \\
\hline 3 & $>41$ tahun & 0 & 0 \\
\hline \multicolumn{2}{|c|}{ Total } & 22 & 100 \\
\hline
\end{tabular}

Sumber : data primer

Berdasarkan Tabel 1.1 di atas menunjukan bahwa jumlah perawat IGD yang berusia 20-30 tahun merupakan paling banyak yaitu berjumlah 15 orang (68\%).

b. Distribusi Data Perawat IGD Berdasarkan tingkat Pendidikan Tabel 1.2 Distribusi Perawat IGD Berdasarkan Pendidikan

\begin{tabular}{|c|c|c|c|}
\hline No & Pendidikan & Jumlah & Porsentase \% \\
\hline 1 & Ners & 5 & 23 \\
\hline 2 & D3 Kep & 15 & 68 \\
\hline 3 & SPK/SMK & 2 & 9 \\
\hline & Total & 22 & 100 \\
\hline
\end{tabular}

Sumber : data primer

Berdasarkan Tabel 1.2 di atas menunjukkan bahwa responden sebagian besar berpendidikan D3 dengan jumlah 15 orang perawat $(68 \%)$.

c. Distribusi Data Perawat IGD Berdasarkan Jenis Kelamin 
Tabel 1.3 Distribusi Perawat IGD berdasarkan Jenis Kelamin

\begin{tabular}{|c|c|c|c|}
\hline No & $\begin{array}{c}\text { Jenis } \\
\text { kelamin }\end{array}$ & Jumlah & $\begin{array}{c}\text { Porsentase } \\
\%\end{array}$ \\
\hline 1 & Laki-laki & 12 & 72 \\
\hline 2 & Perempuan & 10 & 28 \\
\hline & Total & 22 & 100 \\
\hline
\end{tabular}

Sumber : data primer

Berdasarkan Tabel 1.3 di atas menunjukan bahwa jumlah perawat laki-laki lebih dominan dibandingkan perawat perempuan yaitu sebanyak 12 orang (72\%).

d. Distribusi Data Perawat IGD Berdasarkan Masa Kerja Tabel 1.4 Distribusi Perawat IGD Berdasarkan Masa Kerja

\begin{tabular}{|c|c|c|c|}
\hline No & $\begin{array}{c}\text { Masa } \\
\text { Kerja }\end{array}$ & Jumlah & $\begin{array}{c}\text { Porsentase } \\
\%\end{array}$ \\
\hline 1 & $1-5$ tahun & 16 & 73 \\
\hline 2 & $6-10$ tahun & 5 & 23 \\
\hline 3 & $>11$ tahun & 1 & 4 \\
\hline \multicolumn{2}{|c|}{ Total } & 22 & 100 \\
\hline
\end{tabular}

Sumber : kuesioner

BerdasarkanTabel 1.4 di atas menunjukkan bahwa sebagian besar responden memiliki masa kerja dengan kisaran 1 - 5 tahun yaitu dengan jumlah 16 orang $(73 \%)$.

\section{Data khusus}

Data khusus menyajikan hasil yang menggambarkan tentang hubungan pengetahuan perawat tentang gagal jantung dengan penatalaksanaan pasien gagal jantung.

a. Distribusi Data Perawat IGD Berdasarkan Pengetahuan

Tabel 2.1 Distribusi Data Perawat IGD Berdasarkan Pengetahuan Perawat

Sumber : kuesioner

Berdasarkan Tabel 2.1 di atas menunjukan bahwa sebagian besar pengetahuan perawat dalam kategori kurang sebanyak 16 responden $(73 \%)$, cukup 5 responden $(23 \%)$ dan kategori baik sebanyak 1 responden (4\%).

b. Tingkat Tindakan Penataksanaan Pasien Gagal Jantung di IGD RSUD Sumbawa Besar.

Tabel 2.2 Distribusi Responden Berdasarkan Tingkat tindakan penataksanaan pasien gagal jantung di IGD Sumbawa Besar.

\begin{tabular}{|c|c|c|c|}
\hline No & $\begin{array}{c}\text { Tingkat } \\
\text { penatalaksanaan } \\
\text { pasien gagal } \\
\text { jantung }\end{array}$ & Jumlah & $\begin{array}{c}\text { Persentase } \\
(\%)\end{array}$ \\
\hline 1 & Baik & 3 & 14 \\
\hline 2 & Cukup & 5 & 36 \\
\hline 3 & Kurang & 14 & 50 \\
\hline \multicolumn{2}{|c|}{ Total } & 22 & 100 \\
\hline
\end{tabular}

Sumber : Data primer

Tabel 2.2 menunjukkan bahwa penatalaksanaan responden yang kurang yaitu sebanyak $14 \quad$ (50\%), penatalaksanaan yang cukup yaitu sebanyak 5 orang $(36 \%)$ dan yang penatalaksanaan baik yaitu sebanyak 3 (14\%).

\begin{tabular}{|c|c|c|c|}
\hline No & $\begin{array}{c}\text { Pengetahuan } \\
\text { perawat }\end{array}$ & Jumlah & $\begin{array}{c}\text { Prosentase } \\
\%\end{array}$ \\
\hline 1 & Baik & 1 & 4 \\
\hline 2 & Cukup & 5 & 23 \\
\hline 3 & Kurang & 16 & 73 \\
\hline & Total & 22 & 100 \\
\hline
\end{tabular}

c. Analisa Hubungan Pengetahuan Perawat Tentang Gagal Jantug Dengan Penatalaksanan Pasien Gagal Jantung di IGD RSUD Sumbawa Besar. .

Tabel 2.3 Tabulasi Silang Analisa Hubungan pengetahuan perawat tentang gagal jantug dengn penatalaksanan pasien gagal jantung di IGD RSUD Sumbawa Besar. 


\begin{tabular}{|c|c|c|c|c|c|c|c|c|}
\hline & \multicolumn{9}{|c|}{$\begin{array}{c}\text { Tingkat penataksanaan } \\
\text { pasien gagal jantung }\end{array}$} & \multicolumn{2}{c|}{ Total } \\
\cline { 2 - 8 } & \multicolumn{2}{|c|}{$\begin{array}{c}\text { Baik } \\
(76-100 \%)\end{array}$} & \multicolumn{2}{c|}{$\begin{array}{c}\text { Cukup } \\
(56-75 \%)\end{array}$} & \multicolumn{2}{c|}{$\begin{array}{c}\text { Kurang } \\
(<56 \%)\end{array}$} & \multicolumn{2}{|c|}{} \\
\hline $\begin{array}{c}\text { Pengetahuan } \\
\text { perawat }\end{array}$ & $\mathrm{N}$ & $\%$ & $\mathrm{~N}$ & $\%$ & $\mathrm{~N}$ & $\%$ & $\mathrm{~N}$ & $\%$ \\
\hline Baik & 1 & 4,5 & 0 & 0 & 0 & 0 & 1 & 4 \\
\hline Cukup & 1 & 4,5 & 3 & 18 & 1 & 4,5 & 5 & 23 \\
\hline Kurang & 1 & 4,5 & 2 & 4,5 & 13 & 63 & 16 & 73 \\
\hline Total & 3 & 14 & 5 & 23 & 14 & 67,5 & 22 & 100 \\
\hline
\end{tabular}

Sumber : Data Primer

Tabel 2.3 menunjukkan bahwa dari 3 responden dengan tingkat penatalaksanaan baik, dimana yang mempunyai pengetahuan baik terdapat 1 responden $(4,5 \%)$, pengetahuan cukup terdapat 1 responden $(4,5 \%)$, pengetahuan kurang terdapat 1 responden $(4,5 \%)$. Selanjutnya dari 5 responden dengan tingkat penatalaksanaaan cukup dimana yang mempunyai pengetahuan cukup terdapat 3 responden $(4,5 \%)$, pengetahuan kurang 2 responden (9\%), selanjutnya dari 14 responden (64\%, dengan penatalaksanaan kurang berjumlah 13 responden yaitu responden $(56 \%)$.

d. Tabel 2.4 Hasil Uji Korelasi Spearman Rank Hubungan pengetahuan perawat tentang gagal jantug dengn penatalaksanan pasien gagal jantung di IGD RSUD Sumbawa

Besar

\begin{tabular}{|c|c|l|}
\hline $\mathrm{r}$ hitung & $\mathrm{r}$ table & \multicolumn{1}{|c|}{ Interpretasi } \\
\hline 0,4602 & 0,428 & $\begin{array}{l}\mathrm{r} \text { hitung }>\text { r tabel }(0,4602> \\
0,428) \text { maka Ho ditolak dan }\end{array}$ \\
& & $\begin{array}{l}\text { Ha diterima berarti ada } \\
\text { hubungan yang signifikan } \\
\text { antara pengetahuan perawat }\end{array}$ \\
& & $\begin{array}{l}\text { tentang gagal jantug dengan } \\
\text { penatalaksanan pasien gagal } \\
\text { jantung di IGD RSUD } \\
\text { Sumbawa Besar. }\end{array}$ \\
\hline
\end{tabular}

Sumber : Data primer

Tabel 2.4 menunjukkan bahwa hasil analisa statistik dengan menggunakan Uji Korelasi Spearmen Rank dimana diperoleh Rho hitung 0,4602, (lampiran 12) dengan taraf signifikan $5 \% \quad(0,05)$ diperoleh Rho tabel sebesar 0,428. Karena Rho hitung > Rho tabel $(0,4602$ $>0,428$ ) maka Ho ditolak dan $\mathrm{Ha}$ diterima artinya ada hubungan pengetahuan perawat tentang gagal jantug dengn penatalaksanan pasien gagal jantung di IGD RSUD sumbawa besar.

\section{PEMBAHASAN}

\section{Data umum}

a. Identifikasi responden berdasarkan umur

Usia akan mempengaruhi pemikiran seseorang, semakin cukup umur, tingkat kematangan dan kekuatan seseorang akan lebih matang dalam berfikir dan bekerja. Makin tua usia seseorang semakin konstruktif dalam menggunakan koping terhadap masalah yang dihadapi (Jamal, 2006).

Hasil penelitian (tabel 1.1) menunjukkan bahwa pengetahuan perawat tentang gagal jantung dengan penatalaksanaan pasien gagal jantung menunjukkan bahwa sebagian besar responden yang berpengetahuan cukup adalah responden dengan kisaran usia 2030 tahun yaitu berjumlah 15 responden (68\%). Dengan demikian pada usia ini memungkinkan individu untuk belajar dan mencari informasi untuk meningkatkan pengetahuan.

b. Identifikassi responden berdasarkan pendidikan

Status pendidikan yang baik membuat seseorang mampu merespon masalah dengan baik sehingga membentuk pemikiran 
yang baik dalam melakukan tindakan untuk memecahkan masalah. Tingkat pendidikan yang baik dan status pekerjaan yang baik membuat seseorang memiliki kesempatan untuk mendapatkan pengalaman baru dan dapat membentuk pribadi individu (Jamal, 2006).

Pendidikan berpengaruh pada pengetahuan karena makin tinggi pendidikan seseorang pengetahuannya juga semakin tinggi. Akan tetapi perlu ditekankan pula bukan berarti seorang dengan pendidikan rendah mutlak berpengetahuan rendah. Karena meningkatkan pengetahuan tidak mutlak dengan menempuh pendidikan formal tetapi juga dapat diperoleh dari pendidikan nonformal.

Berdasarkan tabel 1.2, hasil penelitian menunjukkan sebagian besar responden berpengetahuan cukup yaitu responden yang mempunyai pendidikan D3 yaitu sebesar 15 responden (68\%).

c. Identifikassi responden berdasarkan lama kerja

Masa kerja merupakan salah satu faktor dari kesiapan perawat dan dapat mempengaruhi tingkat pengetahuan. Semakin banyak masa kerja semakin banyak juga pengalaman perawat tersebut dalam memberikan asuhan keperawatan yang sesuai dengan standar atau prosedur tetap yang berlaku (Nursalam, 2008).

Dari hasil penelitian (tabel 1.4) menunjukkan bahwa sebagian besar responden yang berpengetahuan cukup memiliki masa kerja 1-5 tahun yaitu sebanyak 16 responden (72\%).Dari berbagai pernyataan di atas dapat di simpulkan bahwa semakin lama perawat yang bekerja di IGD, maka pengalaman perawat semakin meningkat.

2. Data khusus

a. Pengetahuan Perawat Tentang Gagal jantung Dengan Penatalaksaan Pasien Gagal Jantung di IGD RSUD Sumbawa Besar.

Pengetahuan tentang tugas merupakan domain yang sangat penting bagi setiap perawat untuk memberikan pelayanan kepada pasien. Pengetahuan yang baik tentang tugas dan tanggung jawab di dalam suatu organisasi cenderung akan meningkatkan kualitas pekerjaannya.

Berdasarkan Tabel 2.1 menunjukan bahwa sebagian besar pengetahuan perawat dalam kategori kurang sebanyak 16 responden (73\%), cukup 5 responden $(23 \%)$ dan kategori baik sebanyak 1 responden (4\%).

Pengetahuan adalah hasil dari tahu dan ini terjadi setelah orang melakukan penginderaan terhadap suatu obyek tertentu. Penginderaan terjadi melalui panca indera manusia yaitu indra penglihatan, pendengaran, penciuman, rasa dan peraba. Pengetahuan pada dasarnya terdiri dari sejumlah fakta dan teori yang memungkinkan seseorang untuk dapat memecahkan masalah yang dihadapi. Pengetahuan tersebut diperoleh baik dari sejumlah yang dihadapi, pengetahuan maupun keyakinan, keduanya merupakan respon mental seseorang dalam respon objek tertentu yang disadari sebagai 'ada' atau terjadi (Notoatmodjo, 2010).

Menurut pendapat Notoatmodjo (2003) bahwa 
pengetahuan merupakan hasil tahu, dan ini terjadi setelah orang melakukan pengindraan terhadap suatu obyek tertentu. Pengindraan terjadi melalui panca indra manusia, yakni penglihatan, pendengaran, penciuman, rasa dan raba. Sebagian besar pengetahuan diperoleh melalui mata dan telinga. Pengetahuan berkenaan dengan bahan yang telah di pelajari sebelumnya atau mengingat kembali tentang informasi yang telah diterima sebelumnya, dalam hal ini pengetahuan perawat tentang gagal jantung. Pengetahuan atau kognitif merupakan domain yang sangat penting untuk terbentuknya tindakan seseorang.

Dalam penelitian ini dapat dilihat bahwa tingkat pengetahuan perawat dapat ditingkatkan melalui pengalaman dan intraksi individu dan lingkunganya (Notoatmadjo, 2003).

Uraian di atas menunjukkan bahwa kurangnya pegetahuan tentang penatalaksanaan pasien Gagal Jantung, disamping itu karena tidak adanya perawat khusus yang ditugaskan memberikan pelayanan kepada pasien Gagal Jantung, sehingga berpengaruh terhadap kinerja mereka, kenyataan ini merupakan sesuatu yang harus dipertimbangkan oleh manajemen rumah sakit.

Pengaruh variabel pengetahuan terhadap kinerja, sesuai dengan pendapat Kusnanto (2004) yang mengatakan bahwa pengetahuan merupakan pemahaman lisan seseorang pegawai tentang apa yang dia ketahui dari pengalaman dan proses belajar. Apabila pegawai tersebut memiliki pengetahuan yang baik tentang pekerjaannya, maka dia akan dapat menyelesaikan pekerjaan tersebut dengan baik, dan demikian sebaliknya.

b. Tindakan Penatalaksanaan Perawat Tentang Gagal jantung Dengan Penatalaksaan Pasien Gagal Jantung di IGD RSUD Sumbawa Besar.

Tabel 2.2 menunjukkan bahwa penatalaksanaan responden yang kurang yaitu sebanyak $11 \quad$ (50\%), penatalaksanaan yang cukup yaitu sebanyak 8 responden (36\%) dan yang penatalaksanaan baik yaitu sebanyak 3 (14\%).

Gagal jantung merupakan sindrom klinis yang kompleks dengan gejala - gejala yang tipikal dari sesak napas (dispneu) dan mudah lelah (fatique) yang dihubungkan dengan kerusakan fungsi maupun struktur dari jantung yang mengganggu dari kemampuan ventrikel untuk mengisi dan mengeluarkan darah ke sirkulasi. Gagal jantung umumnya didapat pada populasi usia tua dan pada infark miokard dengan kerusakan otot jantung persisten (Syamsudin, 2011).

Menurut Notoatmodjo (2003) mengatakan bahwa menerapkan atau aplikasi merupakan kemampuan menggunakan suatu bahan yang telah dipelajari kedalam situasi baru atau yang lebih konkrit, seperti menerapkan suatu dalil, metode, konsep teori, atau prinsip. Hal ini dapat dipengaruhi oleh beberapa faktor diantaranya adalah pemahaman, dimana kapasitas seseorang individu untuk mengerjakan berbagai 
tugas dalam pekerjaan yang pada hakekatnya terdiri dari kemampuan intelektual dan kemampuan fisik. Dalam penelitian ini dapat di lihat setiap perawat memiliki kekuatan dan kelemahn masing-masing dalam hal kemampuan melaksanakan tindakan gagal jantung, maka merupakan satu kewajaran bila ada perawat yang merasa mampu atau tidak mampu melakukan pekerjaan tersebut sesuai ketentuan.

Dengan demikian walaupun penatalaksanaan gagal jantung di ruang IGD RSUD Sumbawa Besar telah di laksnakan namun tindakan perawatnya masih belum optimal karena ada sebagian responden melaksanakan tindakan pelaksanaan gagal jantung belum sesuai dengan prosedur penanganan yanag ada. Menurut peneliti hal ini karena belum di pahaminya isi dari instrumen observasi sesuai instrumen Depkes RI (2002).

Keberhasilan perawat dalam penanganan pasien dengan gagal jantung yaitu dipengaruhi oleh lingkungan fisik, fasilitas, pengetahuan, kondisi pasien, peralatan dan tata kerja.

c. Analisa Perawat Tentang Gagal jantung Dengan Penatalaksaan Pasien Gagal Jantung di IGD RSUD Sumbawa Besar.

Tabel 2.4 menunjukkan bahwa hasil analisa statistik dengan menggunakan Uji Korelasi Spearmen Rank dimana diperoleh Rho hitung 0,4602 dengan taraf signifikan 5\% $(0,05)$ dan diperoleh Rho tabel sebesar 0,428 . Karena Rho hitung > Rho tabel $(0,4602>0,428)$ maka Ho ditolak dan Ha diterima artinya ada hubungan pengetahuan perawat tentang gagal jantung dengan penatalaksanan pasien gagal jantung di IGD RSUD Sumbawa Besar.

Tingkat pengetahuan perawat tentang penatalaksanaan gagal jantung memiliki hubungan yang kuat sehingga untuk mewujudkan penatalaksaan gagal jantung yang optimal diperlukan tingkat pengetahuan yang memadai. Karena dengan tingkat pengetahuan yang memadai, perawat dapat melaksanakan tindakan penanganan pasien gagal jantung dengan baik dan benar.

Dalam penelitian ini sebagian besar perawat memiliki tingkat pengetahuan yang kurang dengan penatalaksanaan gagal jantung masih kurang karena belum melaksanakan penanganan gagal jantung secara optimal. Hal ini disebabkan karena kurang dipahaminya standar prosedur tindakan penanganan penatalaksanaan gagal jantung yang dikeluarkan oleh Departemen Kesehatan RI.

Pendidikan perawat yang semakin tinggi akan memberikan pengaruh terhadap wawasan dan pengetahuan yang dimiliki. Melalui pendidikan formal, perawat dapat memperoleh informasi yang lebih luas khususnya tentang gagal jantung dengan penatalaksanaan pasien gagal jantung. Selain itu juga pengetahuan perawat tentang gagal jantung dengan penatalaksanaan pasien gagal jantung bisa didapatkan melalui pelatihan dan seminar kesehatan. Mulai pada awal tahun 2010, untuk pertama kalinya pihak 
RSUD Sumbawa Besar menyelenggarakan pelatihan BLS yang melibatkan petugas-petugas kesehatan yang ada di RSUD Sumbawa Besar dan diantaranya petugas yang bekerja di Instalasi Gawat Darurat (IGD).

Disamping faktor pengetahuan penatalaksanaan pasien gagal jantung dipengaruhi juga faktor eksternal yang ada. Hal ini sesuai dengan pendapat Kusnanto 2004, bahwa faktor yang mempengaruhi penatalaksanaan dapat dikategorikan menjadi faktor internal yaitu karakteristik perawat itu sendiri meliputi umur, jenis kelamin, pengetahuan dan motivasi. Sedangkan faktor eksternal terdiri dari karakteristik organisasi, kelompok, pekerjaan dan lingkungan.

Pengetahuan yang dimiliki responden dapat juga diperoleh dari pengalaman. Hal ini sesuai dengan pendapat Notoatmodjo 2003, yaitu pengetahuan erat dengan perilaku manusia yakni sebagai bentuk pengalaman dan interaksi individu dengan lingkungan. Pengalaman belajar dalam bekerja yang dikembangkan memberikan pengetahuan dan keterampilan profesional serta pengalaman belajar selama bekerja akan dapat mengembangkan kemampuan mengambil keputusan yang merupakan menifestasi dari keterampilan menalar secara ilmiah dan etis yang bertolak dari masalah nyata dalam bidang keperawatan khususnya tentang penatalaksanaan pasien gagal jantung di IGD RSUD Sumbawa Besar.

\section{KESIMPULAN}

Berdasarkan pembahasan hasil penelitian dapat ditarik kesimpulan sebagai berikut :

1. Pengetahuan perawat, kategori baik 1 responden (4\%), cukup 5 responden (23\%), dan kategori kurang 16 responden $(73 \%)$.

2. Penatalaksanan pasien gagal jantung, kategori baik 3 responden (14\%), cukup 5 responden (36\%), dan kurang 14 responden $(50 \%)$.

3. Ada hubungan yang signifikan antara pengetahuan perawat IGD tentang gagal jantung dengan penatalaksanaan pasien gagal jantung di IGD RSUD Sumbawa Besar.

\section{SARAN}

Meningkatkan pengelolaan dalam penatalaksanaan pada pasien gagal jantung dengan lebih banyak memberikan pelatihan dan update terkait penatalaksanaan Gagal jantung, sehingga angka kematian dan kecacatan akibat gagal jantung dapat diminimalisir. 


\section{DAFTAR PUSTAKA}

Arikunto, S. 2006. Prosedur Penelitian Suatu Pendekatan Praktek. Jakarta; Rineka Cipta.

Buku Panduan Skripsi, 2010/2011. Sekolah Tinggi Kesehatan (STIKES) Mataram Program Studi Ilmu Keperawatan.

Depkes RI, 2002. Teknik perawatan dasar. Jakarta

Direktorat, 2005. keperawatan dan keteknisan medik. Jakarta

Hidayat , Aziz Alimul (2008). Riset keperawatan dan teknik penulisan ilmiah. Edisi 2. Jakarta: Salemba Medika.

Jamal, Sarjani. 2006. Wanita dan pria dalam karakteristik morbilitas morbilitas. Jurnal Epidmologi Nasional.

Krisanty, Manurung, Suratun, Wartonah, Sumartini, Dalami, Rohimah, dan Santun.(2009) Asuhan Keperawatan Gawat Darurat. Jakarta: Trans Info Media.

Kusnanto. 2004. Pengantar profesi dan praktik keperawatan professional. Jakarta; EGC.

Maulana, Mirza. 2012. Penyakit Jantung. Jogjakarta; Katahati.

Musliha. 2010. Keperawatan Gawat Darurat. Yogyakarta; Nuha Medika.

Notoatmodjo, S. 2003, Metodologi Penelitian Kesehatan, Rineka Cipta, Jakarta.

Notoatmodjo, S. 2010. Metodologi penelitian kesehatan. Jakarta; Rineka Cipta.

Nursalam, 2003. Konsep dan Penerapan Metodelogi Penelitian Ilmu Keperawatan. Salemba Medika; Jakarta.

Nursalam, 2008. Konsep Dan Penerapan Metodologi penelitian Ilmu Keperawatan Pedoman Skripsi,Tesis, Dan Instrumen
Penelitian Keperawatan. Jakarta; Salemba Medika.

Profil Kesehatan, Provinsi Nusa Tenggara Barat, 2007. Jumlah Yang Menderita Penyakit Jantung; NTB

Setiadi. 2007. Konsep dan Penulisan Riset Keperawatn. Yogyakarta: Graha Ilmu.

Smeltzer, Susanne C, 2005, Keperawatn Medical Bedah, Vil 1,2,3, EGC, Jakarta.

Sugiyono, 2012. Metode Penelitian Kantitatif Kualitaif Dan R \& D. Bandung; Alfabeta.

Syamsudin. 2011. Buku Ajar Farmakoterapi Kardiovaskuler Dan Renan. Jakarta; Salemba Medika.

Udjianti, 2011, Buku Ajar Keperawatan Kardiovaskuler, Pusat Kesehatan Jantung Pembuluh Darah Nasional, Jakarta.

WHO (2008). World Health Statistic.http//Www.who.int. Diunduh 24 Maret 2012. 